\title{
EARING EVOLUTION DURING DRAWING AND IRONING PROCESSES
}

\author{
P. D. Barros ${ }^{1}$, J.L. Alves ${ }^{2}$, M. C. Oliveira ${ }^{1}$, L. F. Menezes ${ }^{1}$
}

${ }^{1}$ CEMUC, Mechanical Engineering Center of the University of Coimbra, Department of Mechanical Engineering, University of Coimbra (marta.oliveira@ dem.uc.pt)

${ }^{2} \mathrm{CT} 2 \mathrm{M}$, Center for Mechanical and Materials Technologies, Department of Mechanical Engineering, University of Minho

\begin{abstract}
This work presents a study concerning both the deep drawing and ironing processes. The process conditions considered are the ones of the BENCHMARK 1 - Earing Evolution During Drawing and Ironing Processes, proposed under the NUMISHEET 2011 conference. The deep drawing and ironing operations are performed considering two typical body stock materials: $A A 5042$ aluminum alloy and $A K D Q$ steel. The results analyzed are the average cup heights after drawing and ironing processes as well as the required punch load. Two yield criteria were considered: Hill'48 [9] and Cazacu and Barlat, 2001 [3]. The constitutive parameters for the Hill'48 and the Cazacu and Barlat, 2001 were determined based on the experimental results for tensile tests with different orientations to the rolling direction, disk compression test and the equibiaxial tension test, using DD3MAT in-house code. The numerical simulations of the forming process are performed using DD3IMP in-house code. The blank sheet is discretized using 3D solid elements, allowing the accurate description of the contact conditions during the ironing process. The numerical results are compared with the experimental and numerical ones reported in the NUMISHEET 2011 conference proceedings [7]. Globally, the numerical results show that the earing prediction is sensitive to the blank holder modeling, the yield criterion selected, the work hardening law and the strategy used to identify the materials parameters.
\end{abstract}

Keywords: Drawing, Ironing, Yield criterion, DD3IMP.

\section{INTRODUCTION}

Nowadays, can-making processes include drawing, redrawing and several ironing operations. During both drawing and redrawing, the development of the earing phenomenon is directly dependent on the material orthotropic behavior. In fact, anisotropy in sheet metals is mainly due to the noticeable alignment or preferred orientation of crystal-texture that is typically generated during the rolling process. Therefore, the metal flow will be uneven, giving rise to the formation of undulations with a number of high and low spots often designated by ears. The ironing operation, which consists in wall thinning, is known to contribute to the ear- 
ing phenomenon reduction, allowing a more uniform wall thickness of the component as well as increased cup height. Being this process used to produce billions of beverage cans worldwide, various efforts have been made in order to reduce earing, including methods to control the anisotropy in the sheet manufacturing processes such as in rolling and annealing processes [11,12,13,24,34]). Also, Thiruvarudchelvan and Loh, 1994 [27] added an extra annealing process before the drawing process to minimize earing, while [28], Gavas and Izciler, 2006 [8] and $\mathrm{Ku}$ et al., 2007 [16] modified the tool geometry and/or the blank holding system. The blank holding force effect on earing was also studied [6]. Other authors proposed approaches within optimum blank geometry to minimize earing based on numerical simulations $[1,4,5,15,23,29]$ or using analytical approaches $[30,35]$.

In cylindrical deep drawing, a circular blank cut out from a metal sheet is placed concentrically over a die with a cylindrical cavity and drawn by a cylindrical punch. A blank holder pressures the blank during drawing to avoiding wrinkling. The resulting cup has the so-called ears, being the severity dependent of the anisotropic properties of each material. In fact, cup drawing is one of the typical forming operations where the effect of this anisotropy is most evident. Some authors state that the number of ears and the shape of the earing pattern can be correlated with the $r$-values profile [31]. However, Soare et al., 2008 [25] shown that this correlation does not hold generally. In fact, an incorrect description of the $r$-value of the material on the flange area (not at the rim) may affect significantly the profile predictions. Thus, an adequate calibration of the yield surface model leads to more coherent predictions [26]. The seemingly contradictory earing profile predictions previously presented by some authors $[14,23,30]$, may be explained by investigating the corresponding modeling of the biaxial r-values.

The phenomenological description of plastic deformation in metals is the most commonly used strategy in the numerical simulation of forming processes. The main concept to describe the sheet orthotropic behavior is the yield surface, used to describe yielding and the plastic flow of the material. Because of this dual role of the yield surface, particular care and accuracy for its modeling is required. Also, due to the complexity of the underlying mechanism of plastic flow and the increasingly advanced alloying technologies, the yield surface modeling as become more complex, relaying on an increasing number of material parameters [26]. However, some authors noticed that one feature of yield functions with relatively large sets of parameters is that although they are capable of accurate descriptions of the in-plane directional (uniaxial) properties of a metal sheet, they may predict sensibly different plastic properties for neighboring stress states [26].

The focus of this work is to understand the influence of advanced material modeling on the earing evolution prediction during drawing and ironing, for a circular cup proposed under the NUMISHEET 2011 conference [7]. Two typical materials used for can-making were considered in this study: an AA5042 aluminum alloy and an AKDQ steel. The drawing and ironing are performed considering a special die which allows drawing and ironing in one single punch stroke in order to simplify the real process [7]. The same tool geometry is used for both materials. The benchmark results reported include the earing evolution after drawing and after ironing, presenting the cup height evolution with the angle from the rolling direc- 
tion, for each material. Also, the punch force evolution with the punch stroke is presented for both materials [7].

This work presents a comparison between experimental and numerical simulation results obtained for this benchmark. The analysis is performed considering all the results reported in the conference proceedings [7] as well as the ones obtained using the DD3IMP in-house code $[18,21]$. The following section details the model adopted for the numerical simulation of the drawing and ironing test with DD3IMP in-house code. Section 3 presents a discussion of the benchmark, based on the numerical simulations performed with the code DD3IMP and the remarks pointed out by the benchmark participants. The comparison between experimental and numerical simulation results is presented in section 4. Finally, the main conclusions taken of this work are summarized in section 5 .

\section{DD3IMP: DRAWING AND IRONING FE MODEL}

\subsection{Process modeling}

The tools for the drawing and ironing operations consist in a blank holder, a die and a punch, as shown in Figure 1. The die presents a special geometry, enabling the drawing and ironing operations within one punch stroke, in order to simplify the real process. The blank holder force is considered constant throughout the process with a value of $8.9 \mathrm{kN}$, according to the benchmark conditions. The total punch stroke considered is of $72.1 \mathrm{~mm}$.

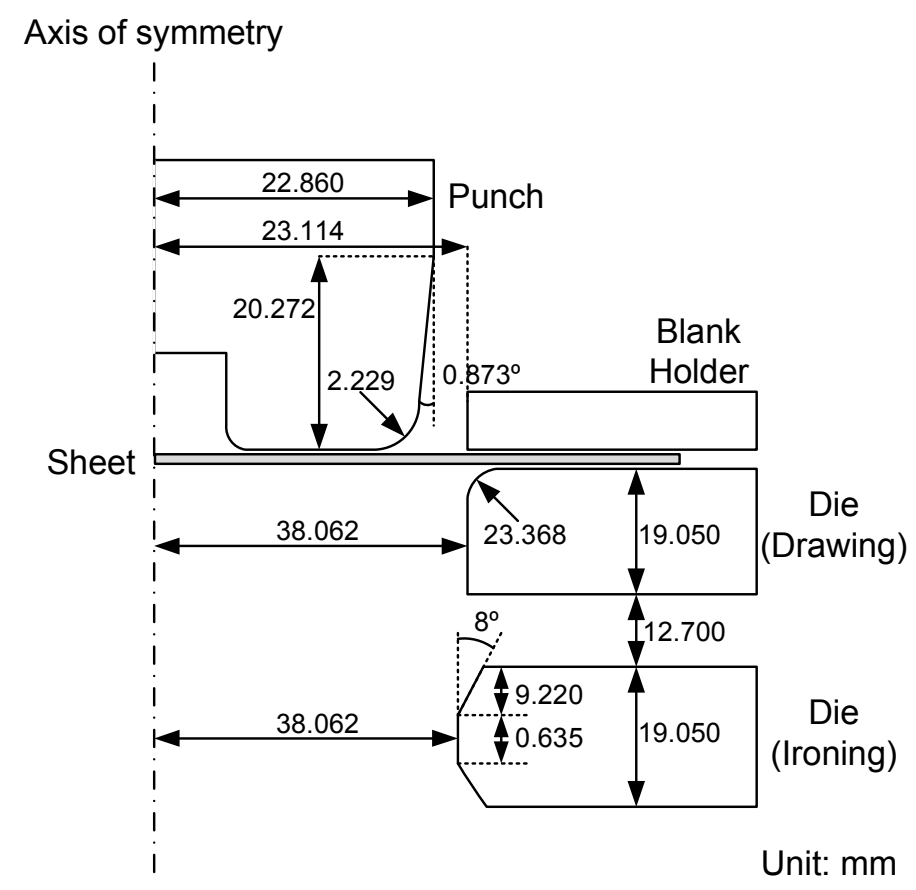

Figure 1. Forming tools geometry and main dimensions.

In the numerical model adopted, only one quarter of the global structure was modeled due to geometrical and material symmetry. All tools were considered rigid and were modeled 
using Bézier surfaces. The contact with friction conditions is described with the Coulomb's law, using the constant friction coefficient value, $\mu$, of 0.05 , according to the benchmark description [7]. The process was modeled considering three phases: (i) closing the blank holder until attaining the impose value of force; (ii) the punch displacement of $72.1 \mathrm{~mm}$ and (iii) the springback, which was modeled considering the "One step springback strategy" [20]. Thus, the springback occurring between the drawing and the ironing stage can be understood as a simple continuation of the forming process.

Although not mentioned in the benchmark description, the model also considered a blank displacement stopper, in order to avoid excessive thinning of the blank outer surface, during the drawing phase. The stopper thickness was assumed as being equal to the blank initial thickness.

\subsection{Material mechanical behavior}

The material's mechanical behavior is assumed to be isotropic in the elastic regime, being described by the Young's modulus, E, and the Poisson ratio, $v$. The plastic behavior is described using a yield criterion, a work hardening behavior law and an associated flow rule. The isotropic work hardening behavior is modeled by the Voce hardening law,

$$
Y\left(\bar{\varepsilon}^{\mathrm{p}}\right)=Y_{0}+\left(Y_{s a t}-Y_{0}\right)\left[1-\exp \left(-C_{Y} \bar{\varepsilon}^{\mathrm{p}}\right)\right]
$$

where $Y$ is the flow stress, $\overline{\mathcal{\varepsilon}}^{\mathrm{p}}$ is the equivalent plastic strain and $Y_{0}$ (yield stress), $Y_{\text {sat }}$ and $C_{Y}$ are material parameters. The isotropic work hardening law adopted for both materials corresponds to the one identified by the benchmark committee for the tensile test performed with the specimen oriented along the rolling direction. adopted,

Regarding the yield criterion, the commonly used Hill' 48 [9] yield criterion was

$$
F\left(\sigma_{y y}-\sigma_{z z}\right)^{2}+G\left(\sigma_{z z}-\sigma_{x x}\right)^{2}+H\left(\sigma_{x x}-\sigma_{y y}\right)^{2}+2 L \sigma_{y z}^{2}+2 M \sigma_{x z}^{2}+2 N \sigma_{x y}^{2}=Y^{2} .
$$

where $F, G, H, L, M$ and $N$ are the anisotropy parameters and $\sigma_{i j}, i, j=1,2,3$ are the stress components defined in the material's frame. For metallic sheets, it is not possible to determine the $L$ and $M$ parameters. Therefore, in order to simplify the problem, the values considered for those parameters are the ones used for isotropic behavior: $L=M=1.5$.

The other criterion used in this work is the Cazacu and Barlat, 2001 [3] generalization to orthotropic behavior of the Drucker's yield criterion,

$$
\left(J_{2}^{0}\right)^{3}-c\left(J_{3}^{0}\right)^{2}=27\left(\frac{Y}{3}\right)^{6} \text {. }
$$

where $J_{2}^{0}$ and $J_{3}^{0}$ are the second and third generalized invariants, given as follows

$$
J_{2}^{0}=\frac{a_{1}}{6}\left(\sigma_{x x}-\sigma_{y y}\right)^{2}+\frac{a_{2}}{6}\left(\sigma_{y y}-\sigma_{z z}\right)^{2}+\frac{a_{3}}{6}\left(\sigma_{x x}-\sigma_{z z}\right)^{2}+a_{4} \sigma_{x y}^{2}+a_{5} \sigma_{x z}^{2}+a_{6} \sigma_{y z}^{2}
$$




$$
\begin{aligned}
J_{3}^{0}= & \frac{1}{27}\left(b_{1}+b_{2}\right) \sigma_{x x}^{3}+\frac{1}{27}\left(b_{3}+b_{4}\right) \sigma_{y y}^{3}+\frac{1}{27}\left[2\left(b_{1}+b_{4}\right)-b_{2}-b_{3}\right] \sigma_{z z}^{3} \\
& -\frac{1}{9}\left(b_{1} \sigma_{y y}+b_{2} \sigma_{z z}\right) \sigma_{x x}^{2}-\frac{1}{9}\left(b_{3} \sigma_{z z}+b_{4} \sigma_{x x}\right) \sigma_{y y}^{2} \\
& -\frac{1}{9}\left[\left(b_{1}-b_{2}+b_{4}\right) \sigma_{x x}+\left(b_{1}-b_{3}+b_{4}\right) \sigma_{y y}\right] \sigma_{z z}^{2}+\frac{2}{9}\left(b_{1}+b_{4}\right) \sigma_{x x} \sigma_{y y} \sigma_{z z} \\
& -\frac{\sigma_{x z}^{2}}{3}\left[2 b_{9} \sigma_{y y}-b_{8} \sigma_{z z}-\left(2 b_{9}-b_{8}\right) \sigma_{x x}\right] \\
& -\frac{\sigma_{x y}^{2}}{3}\left[2 b_{10} \sigma_{z z}-b_{5} \sigma_{y y}-\left(2 b_{10}-b_{5}\right) \sigma_{x x}\right] \\
& -\frac{\sigma_{y z}^{2}}{3}\left[\left(b_{6}-b_{7}\right) \sigma_{x x}-b_{6} \sigma_{y y}-b_{7} \sigma_{z z}\right]+2 b_{11} \sigma_{x y} \sigma_{y z} \sigma_{x z}
\end{aligned}
$$

Also in this case, it is not possible to determine the $a_{5}, a_{6}, b_{6}, b_{7}, b_{8}, b_{9}$ and $b_{11}$ parameters. Therefore, in order to simplify the problem, the value considered for those parameters is the ones used for isotropic behavior, 1.0.

The parameters for each model were determined using the DD3MAT in-house code [3] taking into account the values reported by the benchmark committee for the uniaxial tensile tests, the equi biaxial tension and the disc compression test. The parameters identification both yield criteria considered the flow stresses and $r$-values in the 7 orientations, the $r_{b}$ value and the biaxial yield stress, $\sigma_{b}$. The identification procedure adopted minimizes an error function that evaluated the difference between the estimated values and the experimental ones. This error function considers that the weight of each experimental value can be different. The conditions that guarantee the convexity of the Cazacu and Barlat, 2001 yield criterion are not known. During the optimization procedure the convexity of the yield surface is tested for the planes $\sigma_{11}, \sigma_{22}$ (with $\left.\sigma_{33}=0\right), \sigma_{11}, \sigma_{33}$ (with $\left.\sigma_{22}=0\right)$ and $\sigma_{22}, \sigma_{33}$ (with $\sigma_{11}=0$ ). The error function associated to estimated non-convex surfaces is strongly penalized, during the optimization procedure.

In this study, the error function considers that all the experimental values have an equal weight of 1.0. For the AA5042, the Cazacu and Barlat, 2001 yield criterion was also identified without taking into account the $\sigma_{b}$ value. Also, in this case equal weights of 1.0 were considered for the fifteen experimental values. Thus, the first identification (labeled as CB) took into account all 16 parameters given by the benchmark committee. The second, labeled as $\mathrm{CB} \sigma_{b}$, was performed considering only fifteen experimental values. Figure 2 presents the comparison between the experimental tensile test results and theoretical predictions for AKDQ steel. Figure 3 presents the same comparison for the AA5042. It is possible to observe that there is a better correlation between the $r$-values than for the normalized yield stress values. 

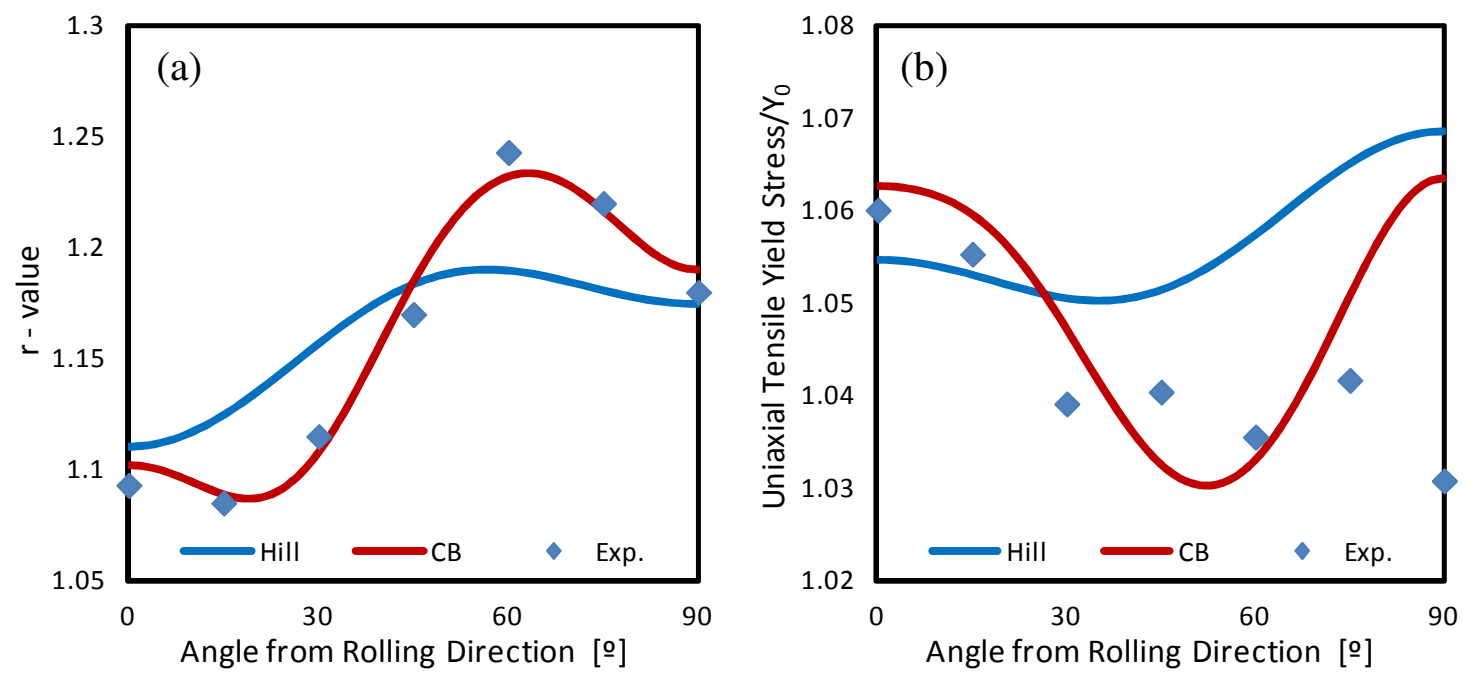

Figure 2. Experimental results in comparison with predictions for AKDQ: (a) $r$-values; (b) normalized yield stress.
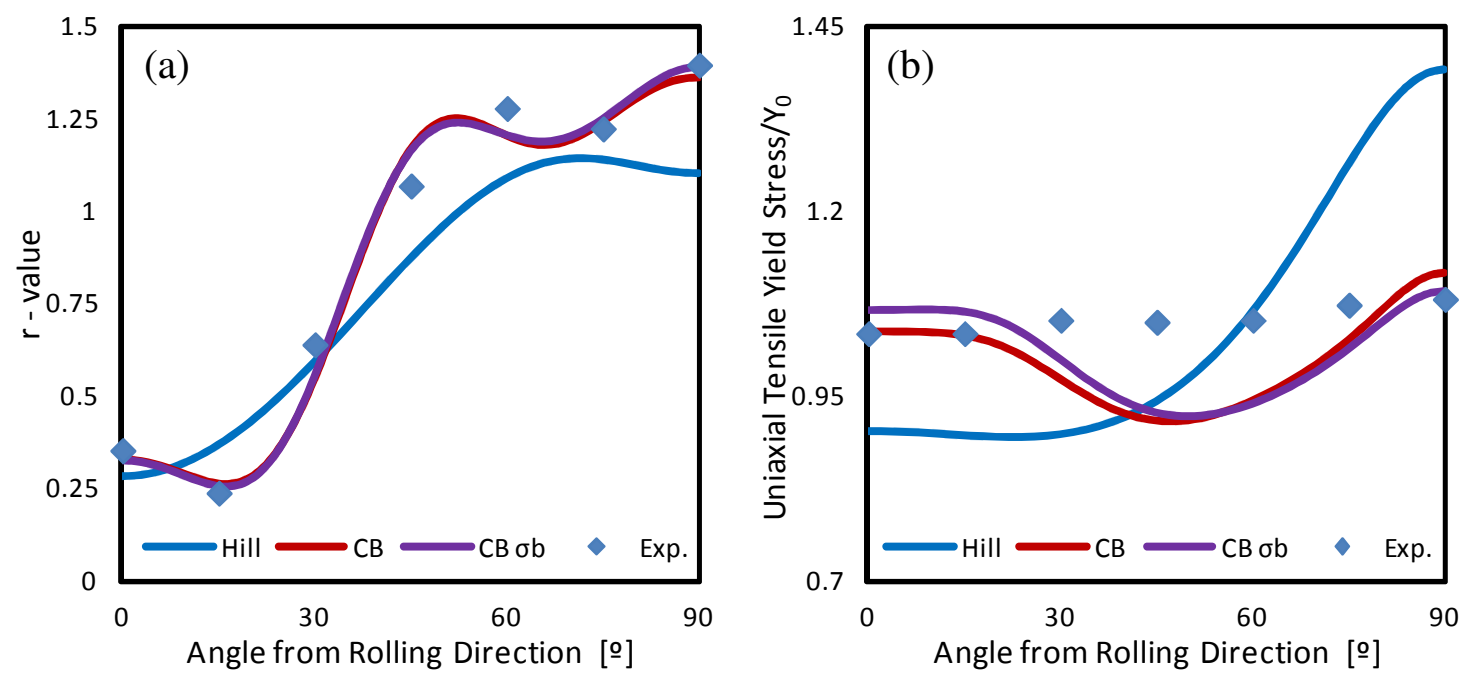

Figure 3. Experimental results in comparison with predictions for AA5042: (a) $r$-values; (b) normalized yield stress.

The experimental value reported for $r_{b}$ for the AKDQ steel is equal to 1.0 and for the AA5042 is 0.991 . For the AKDQ steel, the value predicted by the Hill' 48 yield criterion is 0.945 and by the Cazacu and Barlat, 2001 is 1.006 . The yield surfaces predicted are shown in Figure 4 (a), where it is possible to confirm the similarities between both yield criteria, for this material which is only slightly orthotropic. For the AA5042 aluminum alloy, the value predicted by the Hill' 48 yield criterion is 0.257 and by the $\mathrm{CB}$ is 1.004 while for the $\mathrm{CB} \sigma_{b}$ is slightly lower, 0.978. Figure 4 (b) presents the yield surfaces predicted highlighting that the effect of not using the $\sigma_{b}$ value is more evident in the biaxial stress state. It is interesting to note that the identifications are similar between the pure compression, the shear and the pure stress states. Table 1 presents a summary of the parameters used, for both materials and yield criteria. 

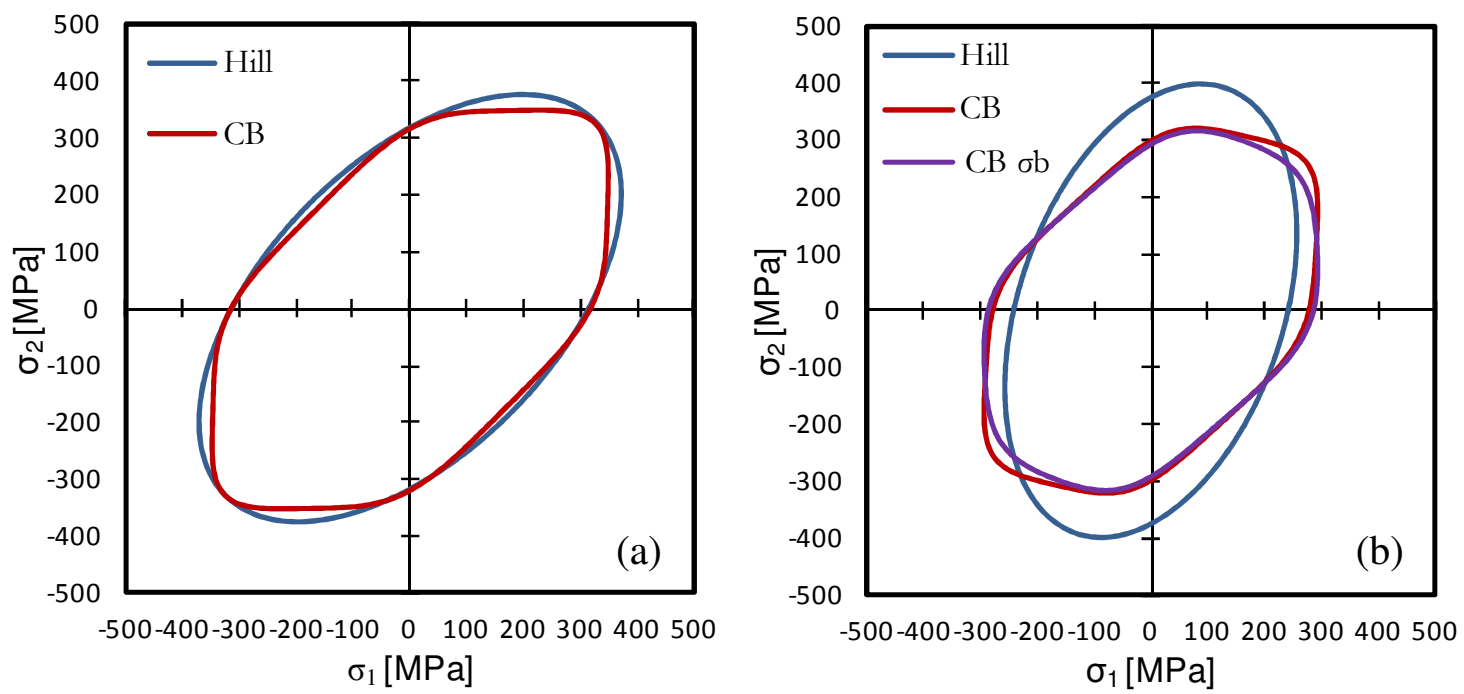

Figure 4. Predicted yield surfaces in the $\sigma_{11}, \sigma_{22}$ (with $\sigma_{33}=0$ ) plane: (a) AKDQ; (b) AA5042.

Table 1. Materials' mechanical properties and constitutive parameters

\begin{tabular}{|c|c|c|c|c|}
\hline \multirow{3}{*}{ Elastic Properties } & & \multicolumn{2}{|c|}{ AA5042 } & AKDQ \\
\hline & $E[\mathrm{MPa}]$ & \multicolumn{2}{|c|}{68900.0} & 210000.0 \\
\hline & $v$ & \multicolumn{2}{|c|}{0.33} & 0.30 \\
\hline \multirow{3}{*}{ Voce Law } & $Y_{0}[\mathrm{MPa}]$ & \multicolumn{2}{|c|}{267.80} & 297.79 \\
\hline & $Y_{s a t}[\mathrm{MPa}]$ & \multicolumn{2}{|c|}{375.08} & 471.76 \\
\hline & $C_{Y}$ & \multicolumn{2}{|c|}{17.859} & 15.886 \\
\hline \multirow{4}{*}{ Hill' 48} & $F$ & \multicolumn{2}{|c|}{0.2457} & 0.4028 \\
\hline & $G$ & \multicolumn{2}{|c|}{0.9553} & 0.4269 \\
\hline & $H$ & \multicolumn{2}{|c|}{0.2704} & 0.4730 \\
\hline & $N$ & \multicolumn{2}{|c|}{1.6459} & 1.3951 \\
\hline \multirow{12}{*}{ CB2001 } & & \multicolumn{2}{|r|}{$\mathrm{CB} \sigma_{b}$} & $\mathrm{CB}$ \\
\hline & $a_{1}$ & 0.8378 & 0.8136 & 1.0496 \\
\hline & $a_{2}$ & 0.9812 & 1.1047 & 0.9568 \\
\hline & $a_{3}$ & 1.2415 & 1.2210 & 0.9681 \\
\hline & $a_{4}$ & 1.2517 & 1.2349 & 1.0560 \\
\hline & $b_{1}$ & 37.4884 & 34.8758 & 1.1731 \\
\hline & $\overline{b_{2}}$ & 9.4583 & 17.8933 & 1.1183 \\
\hline & $b_{3}$ & 31.9364 & 40.8191 & 1.1681 \\
\hline & $b_{4}$ & 8.1418 & 5.1255 & 1.0751 \\
\hline & $b_{5}$ & -18.0791 & -10.9042 & 0.8837 \\
\hline & $b_{10}$ & 15.8896 & 19.9779 & 1.0515 \\
\hline & $c$ & 0.0039 & 0.0038 & 1.7104 \\
\hline
\end{tabular}




\subsection{Blank sheet discretization}

The blank sheet, for both materials, is circular in shape with a radius of $38.062 \mathrm{~mm}$. For the AA5042, the corresponding thickness is of $0.208 \mathrm{~mm}$ while for the AKDQ steel the thickness is of $0.229 \mathrm{~mm}$. Only one quarter of the global structure was modeled due to geometrical and material symmetry. 3-D solid elements with 8 nodes, combined with a selective reduced integration technique, were used to discretize the blank sheet. The use of solid elements allows an accurate prediction of double sided contact with anisotropy. Figure 5 presents the in-plane finite element mesh considered in the analysis. This mesh was built considering two and three elements through thickness, in order to evaluate the influence of the throughthickness description, mainly in the ironing stage in which severe transverse shear deformation occurs.

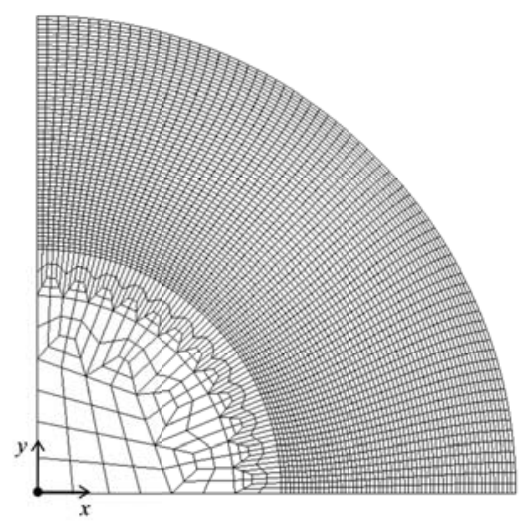

Figure 5. In-plane blank sheet discretization.
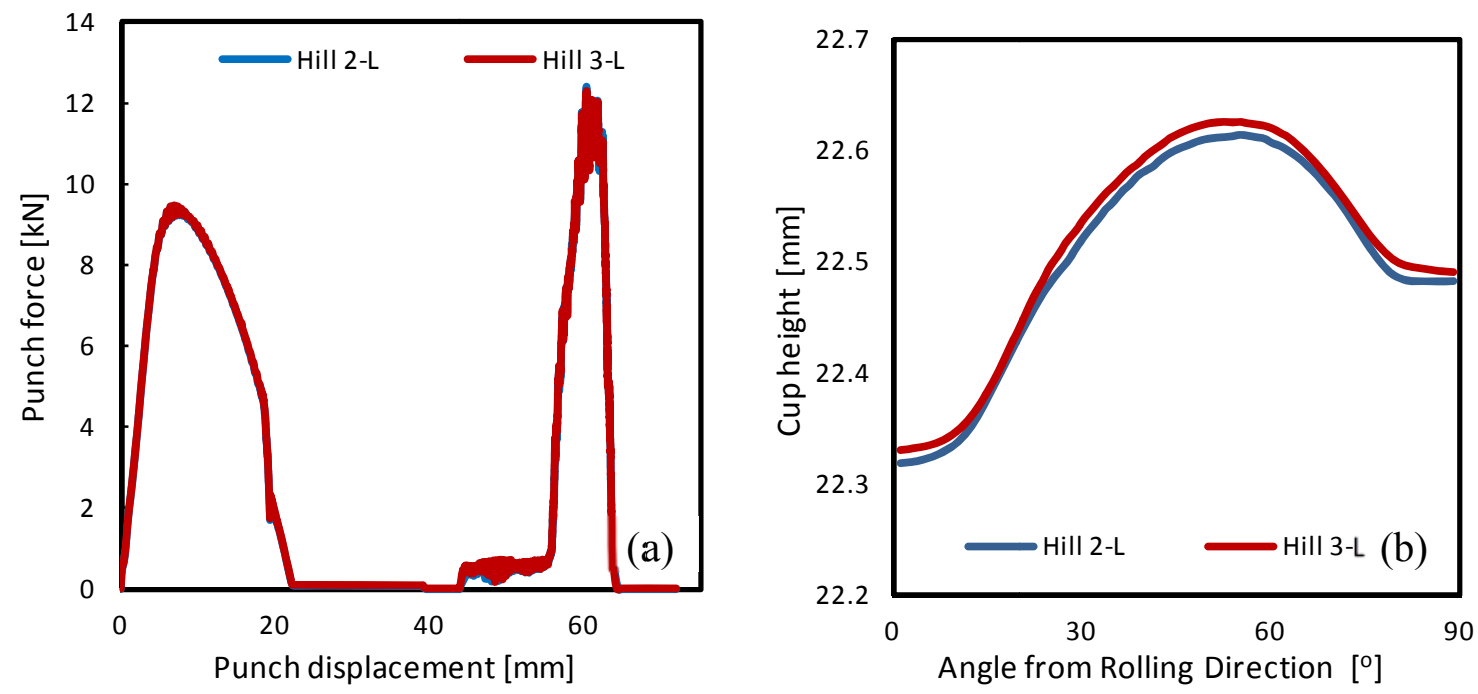

Figure 6. Numerical results obtained for the AKDQ steel using two layers through-thickness (2-L) and three (3-L): (a) punch force evolution; (b) cup height after ironing.

The numerical simulation of the process was performed with both discretizations considering the AKDQ steel, only with the Hill'48 criterion. The punch force evolution predicted 
is presented in Figure 11 (a), being the two layers mesh discretization labeled 2-L and the three by 3-L. Figure 11 (b) presents the cup height evolution after ironing. It is possible to observe that the difference in the punch force evolution and the cup height are negligible. Although not presented here, the cup height after drawing also presents negligible differences. Therefore, in the following analysis the mesh with two layers through-thickness was adopted.

\section{NUMERICAL ANALYSIS OF THE BENCHMARK CONDITIONS}

This section presents an analysis of the drawing and ironing conditions, based on the numerical simulation results obtained with the in-house code DD3IMP [18,21]. The analysis is mainly focused on the contact conditions imposed by the blank holder, during the drawing stage. The algorithm adopted in DD3IMP code for force-controlled tools takes into account the evolution of its spatial position during the deep drawing process, in order to maintain the force-controlled value [17]. Therefore, in the equilibrium iterations of the implicit algorithm, a supplementary equation is added to the linear equations system to be solved, that guarantees that the spatial position of the nodes in contact with the force-controlled tool is the one necessary to impose the force within a tolerance value of $\pm 10 \%$. Also, the use of solid finite elements allows solving the simultaneous contact on both sides of the sheet without any particular strategy. This is particularly important when dealing will tools with imposed force since the contact regions depend on the updated thickness. On the other hand, the thickness evolution of the flange depends directly on the materials' mechanical behavior, particularly the yield criterion, as well from the friction conditions [32, 33]. Figure 7 presents the force and the blank holder displacement evolution during the drawing stage, for the numerical simulations performed for the AKDQ steel.
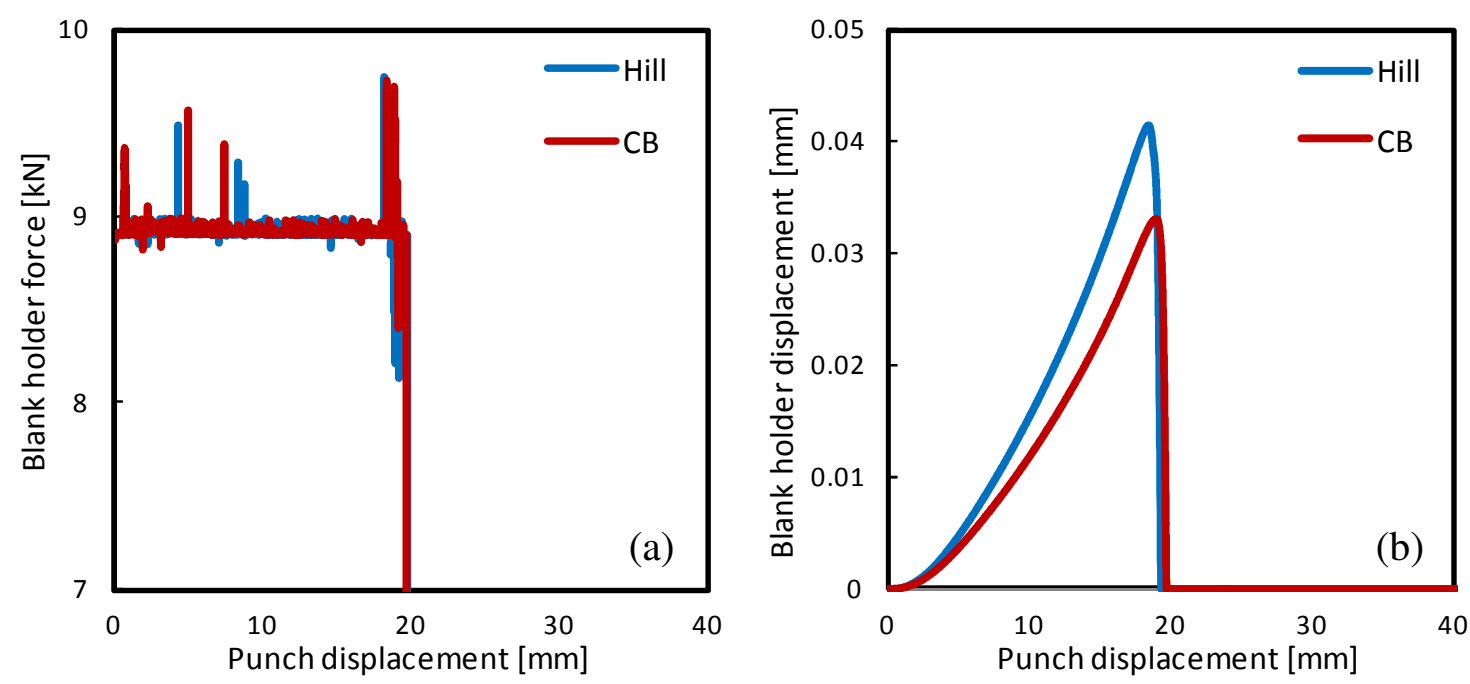

Figure 7. Numerical results obtained for the AKDQ steel: (a) blank holder force and (b) blank holder displacement evolution with the punch displacement during the drawing phase.

It is possible to observe that the blank holder force is kept almost constant during the drawing phase. The blank holder's positive displacement indicates an increase of the gap be- 
tween it and the die, which is associated to an increase of thickness on the flange. The contact area between the sheet and the blank holder reduces with the increase of the punch displacement. Therefore, the blank holder inverts its displacement in order to keep the constant force value. For a punch displacement of approximately $20 \mathrm{~mm}$, the blank holder force contributes to the material flow, which leads to the sudden drop of the punch force, as shown in Figure 6 (a). The use of the blank holder stopper, described previously, prevents the blank holder from attaining a negative displacement and, consequently, the sheet loses contact with the blank holder.

Figure 8 presents the thickness evolution along the cup wall for AKDQ steel and an angle from the rolling direction of $45^{\circ}$ and $90^{\circ}$, at the end of the drawing phase. The results show the thickness decrease near the punch radius and the increase towards the flange. As expected, due to the isotropic behavior of this material, the thickness evolution is similar for the $45^{\circ}$ and the $90^{\circ}$ directions. However, at the flange end there is a sudden drop in thickness, which results from the restraining imposed by the blank holder. The higher thickness reducing along the $45^{\circ}$ to the rolling direction results from the fact that this zone is the last to loose contact with the blank holder. It should be mentioned that this thickness reduction at the flange end would be higher if the blank stopper was not used in the model.
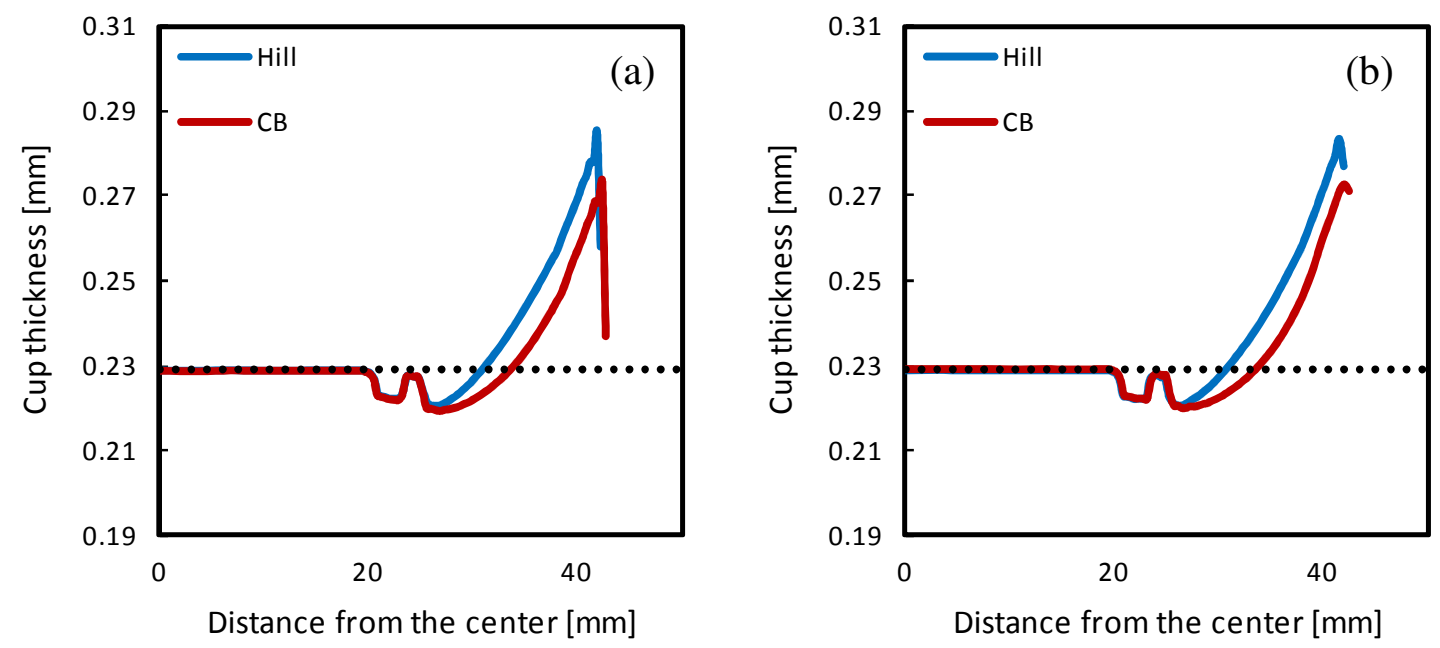

Figure 8. Thickness evolution along the cup wall for AKDQ and an angle from the rolling direction of: (a) $45^{\circ}$; (b) 90 . The dashed line corresponds to the initial thickness.

Figure 9 presents the thickness evolution along the cup wall for AA5042 aluminum alloy, for an angle from the rolling direction of $45^{\circ}$ and $90^{\circ}$, at the end of the drawing phase. In this case, the material orthotropic behavior is reflected in these evolutions. Also in this case, the material located along the $45^{\circ}$ to the rolling direction suffers a higher thickness reduction at the end of the drawing process, since it flows less than the material located along the $90^{\circ}$ direction. 

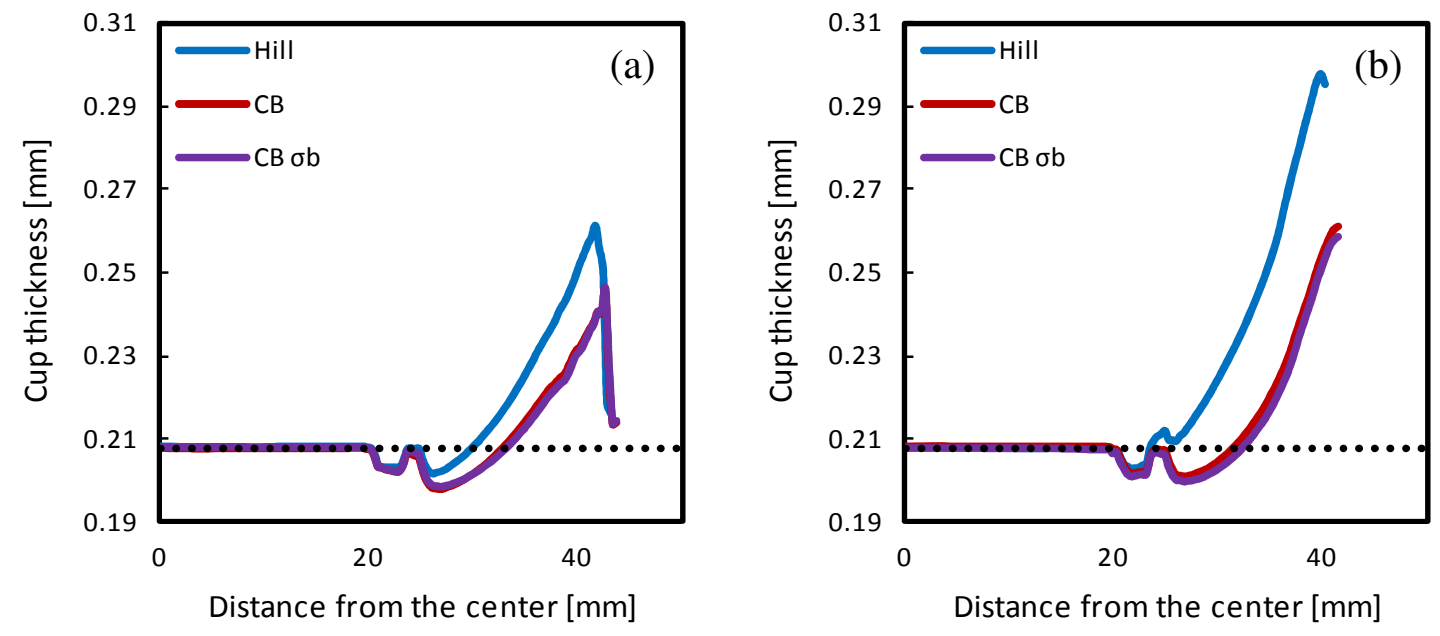

Figure 9. Thickness evolution along the cup wall for AA5042 and an angle from the rolling direction of: (a) $45^{\circ}$; (b) 90 . The dashed line corresponds to the initial thickness.

The stress states of the material located in the flange evolve from pure compression, in the outer radius, to pure tension in the inner radius, passing through the shear state. The earing profile depends on the different levels of radial tensile stresses ("yield stress effect") and the different levels of compressive strains generate different ratios of the radial and thickness strain (" $r$-value effect") [33]. The numerical results show that the contact conditions between the sheet and the blank holder evolve differently, from the beginning of the numerical simulation. To highlight this effect, Figure 10 presents the distribution of the contact force, in the direction corresponding to the punch displacement, for the AKDQ, as predicted using the Hill'48 and the Cazacu and Barlat, 2001, yield criteria.

\begin{tabular}{|l|l|l|l|}
\hline $5 \mathrm{~mm}$ & Hill & CB & \\
\hline & & & \\
5
\end{tabular}

Figure 10. Contact force distribution for the AKDQ for a punch displacement of 5 and 10 $\mathrm{mm}$, as predicted using the Hill' 48 and the Cazacu and Barlat, 2001, yield criteria. 
The results shown a more uniform contact force distribution, along the flange, for the results obtained with the Cazacu and Barlat, 2001, yield criterion.

\section{NUMISHEET 2011 RESULTS COMPARISON}

The numerical simulation of the benchmark was performed by 10 participants using eight different solvers [7]. Some participants provided results for only one material: participant 02 performed the simulation only for the AA5042 material while participant 04 provided results only for the AKDQ material. The summary of the numerical simulation conditions and methods is presented in Table 2. Column "Software" presents the formulation and time integration method adopted in forming, springback after drawing, ironing and springback after ironing phases, respectively, where "S" stands for static, "D" for dynamic, "I" for implicit and "E" for explicit. It should be mentioned that participant 01 used an analytical solution implemented in Excel [19]. All the other participants used the dynamic formulation throughout the numerical simulation of the process, except participant 02 that used a static formulation for the springback after drawing. Also, all participants adopted the Coulomb friction model, except participant 09 which used forming one way surface to surface frictional value. Participant 10 does not indicate the friction model adopted.

The majority of the participants adopted solid elements. However, participant 02 used shell elements throughout the numerical simulation, participant 06 used shell elements only for the AA5042 material and participant 08 used shell elements for the drawing phase of the AA5042 material.

Regarding the materials' mechanical modelling, several work hardening and yield criteria were adopted, including different models for the drawing and ironing phases. However, the majority of the participants adopted the Voce work hardening law, as suggested by the benchmark committee. Also, for the AKDQ the majority of the participants adopted the Hill' 48 criterion.

Two participants contributed with more than one result. Participants 01 presented results using the same constitutive models, but with the parameters identified using different approaches. The results labeled 01A for the AA5042 aluminum alloy were obtained with the parameters identified using the $r$-values from the tensile tests and the stress ratio by comparing the uniaxial yield stresses at $0.5 \mathrm{MPa}$ plastic work $(0.2 \%$ equivalent plastic strain; initial yield). For the AKDQ steel, the same label is used for the parameters identified using the $r$ values from the tensile tests and stress ratio determined by interpretation of the texture data. The results labeled 02A use the parameters identified using the $r$-values from the tensile tests and the stress ratio by comparing the uniaxial yield stresses at a level of plastic work that is close to the end of uniform strain (20 MPa plastic work for AA5042 = average of $6.4 \%$ equivalent strain and 56.5 MPa plastic work for $\mathrm{AKDQ}=$ average of $14 \%$ equivalent strain). 
Table 2. Summary of simulation conditions and methods.

\begin{tabular}{|c|c|c|c|c|c|}
\hline Number & $\begin{array}{l}\text { Software } \\
\text { Formulation adopted }\end{array}$ & Element type & Yield criteria & Hardening law & Other remarks \\
\hline $\begin{array}{l}01 \mathrm{~A} \\
01 \mathrm{~B}\end{array}$ & $\begin{array}{l}\text { Analytical solution im- } \\
\text { plemented in Excel }\end{array}$ & N.A. & Hosford (drawing); Hill’ 48 (ironing) & $\begin{array}{l}\text { Isotropic. Voce (AA5042); } \\
\text { Swift (AKDQ) }\end{array}$ & $\begin{array}{l}\text { Coulomb friction } \\
\text { Elastic blank holder }\end{array}$ \\
\hline $\begin{array}{l}02 \mathrm{~A} \\
02 \mathrm{~B} \\
02 \mathrm{C}\end{array}$ & $\begin{array}{l}\text { Pam Stamp } 2 \mathrm{G} \\
\text { DE, SI, DE, DE }\end{array}$ & $\begin{array}{l}4 \text { node B-T shell } 9 \text { I.P. } \\
\text { (T.T.S. ironing) }\end{array}$ & Vegter (drawing); Hill' 48 (ironing) & Isotropic. Voce (AA5042) $0^{\circ}$ & Coulomb friction \\
\hline 03 & $\begin{array}{l}\text { ABAQUS Explicit } \\
\text { DE, DE, DE, DE }\end{array}$ & Solid elements C3D8R & СРB06ex2 & Isotropic. Voce & Coulomb friction \\
\hline 04 & $\begin{array}{l}\text { STAMPACK-v7 } \\
\text { DE, DE, DE, DE }\end{array}$ & 8 node solid hex. 4 I.P. & Hill' 48 & $\begin{array}{l}\text { Isotropic. Voce Elasto-plastic 3D model, } \\
\text { hyperelastic, large strains (logarithmic) }\end{array}$ & Coulomb friction \\
\hline 05 & $\begin{array}{l}\text { ABAQUS } \\
\text { DE, DE, DE, DE }\end{array}$ & $\begin{array}{l}8 \text { node cont. brick. Reduced } \\
\text { integration }\end{array}$ & Facet plastic potential & $\begin{array}{l}\text { Swift. Accumulated plastic slip/resolved } \\
\text { shear stress }\end{array}$ & Coulomb friction \\
\hline 07 & $\begin{array}{l}\text { RADIOSS v } 110 \\
\text { DE, DE, DE, DE }\end{array}$ & HEPH Solid. 5 layers. & Hill' 48 & Isotropic Power law & Coulomb friction \\
\hline 08 & $\begin{array}{l}\text { JSTAMP/NV (solver: LS- } \\
\text { DYNA) } \\
\text { DE, DE, DE, DE }\end{array}$ & $\begin{array}{l}\text { B-W-C shell, } 5 \text { I.P. (draw- } \\
\text { ing) Solid } 1 \text { I.P., } 3 \text { layers } \\
\text { (ironing) AA5042 }\end{array}$ & $\begin{array}{l}\text { Gotoh (drawing); von Mises (ironing) } \\
\text { (AA5042) } \\
\text { Hill' } 48 \text { (AKDQ) }\end{array}$ & $\begin{array}{l}\text { Yoshida/Uemori(drawing); Isotropic (iron- } \\
\text { ing) (AA5042); Isotropic (AKDQ) }\end{array}$ & Coulomb friction \\
\hline 09 & $\begin{array}{l}\text { Eta/DYNAFORM } 5.8 \\
\text { DE, DE, DE, DE }\end{array}$ & Quadrilateral and triangular & Planar anisotropic plasticity model & Non-linear hardening rule. Krupskowsky law & $\begin{array}{l}\text { Forming one way surface } \\
\text { to surface frictional value }\end{array}$ \\
\hline 10 & $\begin{array}{l}\text { ABAQUS } 6.10 \\
\text { DE, DE, DE, DE }\end{array}$ & $\begin{array}{l}8 \text { node continuous elements } \\
\text { with reduced integration }\end{array}$ & Yld2004-18p & $\begin{array}{l}\text { Voce. Equibiaxial tension along rolling di- } \\
\text { rection }\end{array}$ & - \\
\hline
\end{tabular}

\footnotetext{
${ }^{(1)}$ Forming, springback after drawing, ironing, springback after ironing
} 
Participant 02 also reported results using the same constitutive models, with the parameters identified using all mechanical test results (tensile tests in 7 directions and bulge tests) at two different amounts of plastic work, which results into two different material input sets. The results labeled $02 \mathrm{~A}$ correspond to an equivalent plastic work amount of $0.5 \mathrm{MPa}$ and the ones labeled $02 \mathrm{~B}$ to $20 \mathrm{MPa}$. This participant points out that for the aluminum alloy a very big influence of local thickening of the blank under the blank holder was observed during drawing. Because thickening was quite high at $90^{\circ}$ to rolling direction the cup height at this area was increased due to much higher friction forces in drawing. On the contrary friction forces were very low or even zero at areas with low thickening under blank holder. For these reason, the results labeled $02 \mathrm{C}$ correspond to the same identification of $02 \mathrm{~A}$, but with a model set-up that provides a more uniformly distributed blank holder pressure by means of a high value of deformation height factor (numerical parameter reducing contact penalty stiffness) [7].

Globally, all participants predicted the same trend for the punch force evolution. In order to quantify the differences, the error between each numerical result and the experimental ones was evaluated, considering a linear regression to evaluate the differences for the same value of displacements. The error in the punch force evolution is evaluated as

$$
\text { Error }_{\text {Force }}=\text { Force }_{\text {Exp. }}-\text { Force }_{\text {Num. }} \text {, }
$$

where Force designates the punch force and the subscripts Exp. and Num. correspond to the experimental and numerical results, respectively. Figure 11 present the global results obtained by all participants and with DD3IMP solver, for the AKDQ material. Except for participant 09, the results show a similar trend with an overestimation of the punch force in the drawing and particularly in the ironing phase. The underestimation of the force for the drawing process indicates that either the work hardening or the friction conditions were also underestimated. Figure 12 present the global results obtained by all participants and with DD3IMP solver, for the AA5042 material. For the AA5042 it is possible to observe that the differences between the numerical and the experimental values can be considered relatively low for the drawing operation. Except for participant 09, the results show a similar trend with an underestimation of the punch force in the drawing and an overestimating in the ironing phase. The results obtained by participant 09 indicate that the dynamics effects were not properly taken into account in the numerical simulation. Therefore, the results presented by this participant are excluded for further analysis.

For the ironing operation the punch force predicted is typically underestimated by all participants and also by DD3IMP results, for both materials. The value of force for this type of operation is very sensitive to the thickness distribution dictated by the drawing operation as well as by the materials' work hardening behavior. To quantify the differences in the maximum punch force, the relative error was evaluated using the following expression,

$$
\text { Error }_{\mathrm{V}}=\frac{\mathrm{V}_{\text {Exp. }}-\mathrm{V}_{\mathrm{Num} .}}{\mathrm{V}_{\text {Exp. }}} \times 100 .
$$


where $\mathrm{V}$ designates the variable under analysis and the subscripts Exp. and Num. correspond to the experimental and numerical results, respectively. In this case the variable under analysis is the maximum punch force and the results are presented in Figure 13. It is possible to observe that even for the nearly isotropic AKDQ material there is a clear underestimation of the maximum value of force. It is also possible to observe that slightly differences are reported for the same constitutive models, with the parameters identified using different approaches. The results that lead not an overestimation (participant 06) and to the higher underestimation (participant 07) indicate the use of the same constitutive model (isotropic power law and Hill' 48 yield criterion). The percentage error for the numerically predicted ironing force for the AA5042 aluminum alloy attains values similar to the ones obtained for the AKDQ. For the AA5042, it is interesting to note that the results obtained with DD3IMP code, although the thickness distribution is very similar at the end of the drawing phase is similar (see Figure 9) for both CB identifications, the model identified without taking the $\sigma_{b}$ value into account predicts a lower maximum value of the maximum ironing force. This seems to be a direct consequent of the different approximation of the yield stress evolution (see Figure 3 (b)).
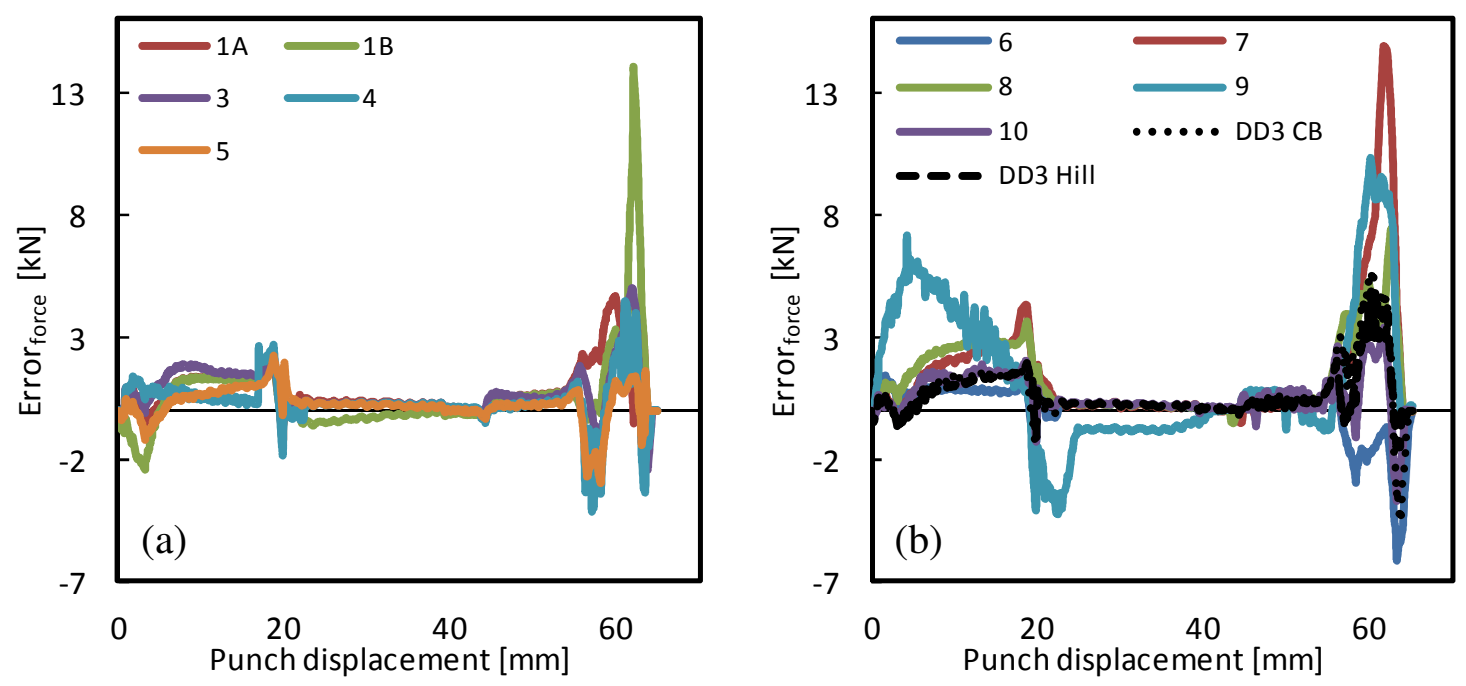

Figure 11. Punch force evolution error for AKDQ material.
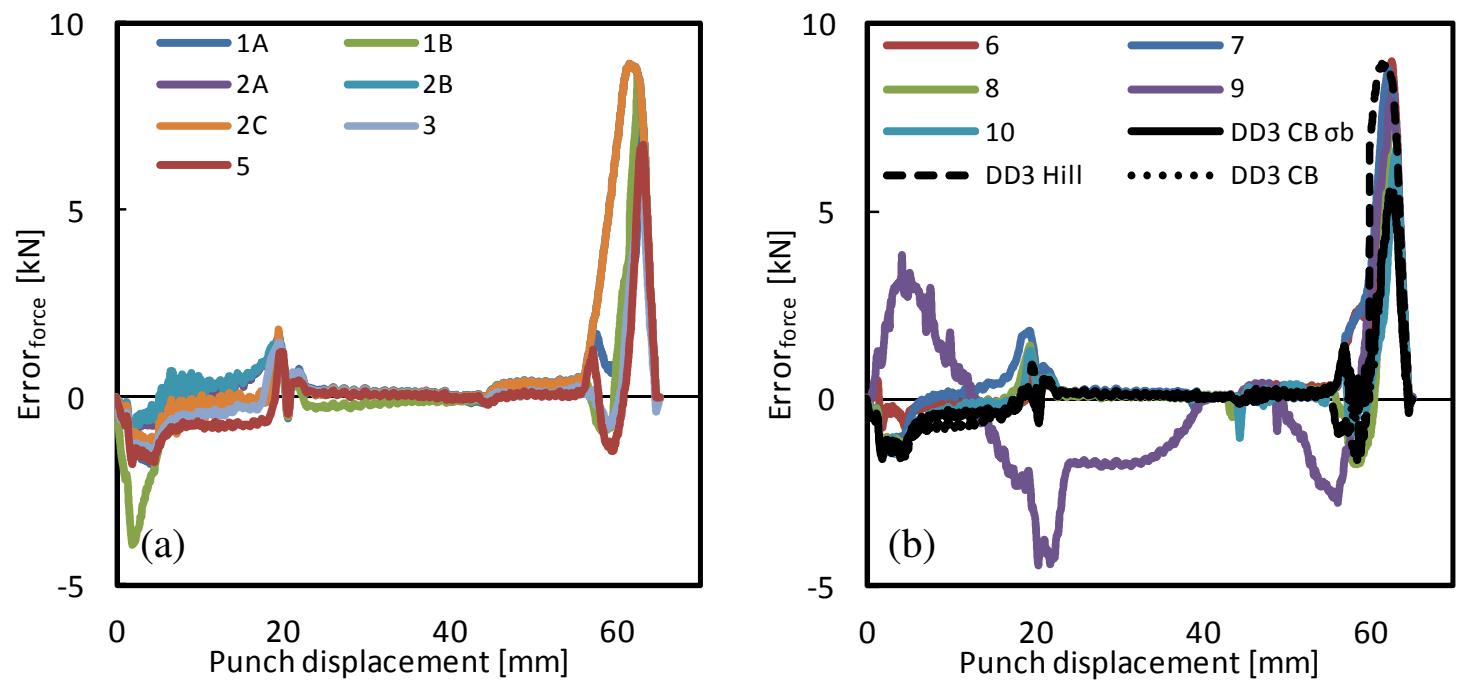

Figure 12. Punch force evolution error for AA5042 material. 

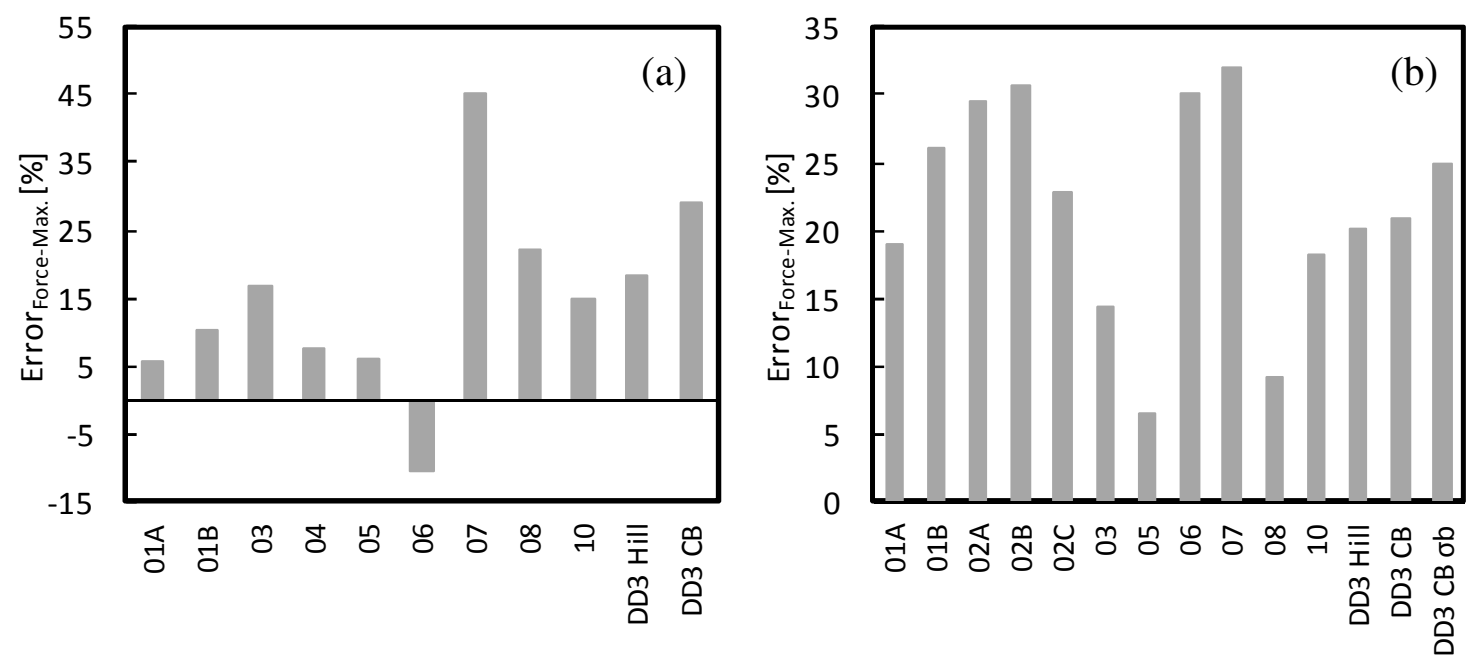

Figure 13. Percentage error for the numerically predicted ironing force for (a) AKDQ and (b) AA5042.

The earing profiles provided by the participants, after the drawing and the ironing operations, were compared with the experimental results provided by the benchmark committee. The results obtained with DD3IMP code were also analyzed. To quantify the differences in the cup height, the relative error was evaluated using equation (7). Thus, a positive relative error corresponds to an underestimation of the experimental height and a negative error to an overestimation. Also, a linear evolution of the shape error with a slope close to zero corresponds to an accurate prediction of the earing profile.

The earing profile height percentage errors for the AKDQ steel are presented in Figure 14 and Figure 15, after drawing and ironing, respectively. Globally, it is possible to observe that the tendency is to overestimate the predicted profile height. Participant 7 seems to deviate from the tendency, showing the higher percentage error after ironing and underestimates the height values. As previously mentioned, the punch force evolution during drawing is underestimated by the majority of the numerical results. However, the cups' height after drawing is globally overestimated. This seems to confirm that the material work hardening is not accurately described, since a higher deformation was predicted for a lower punch force.

Figure 16and Figure 17 present the earing profile height percentage errors for the AA5042, after drawing and ironing, respectively. In this case, it is possible to observe that globally the tendency is to underestimate the predicted profile height, particularly for the rolling and transverse directions. As previously mentioned, in this case the punch force evolution during drawing is overestimated by the majority of the numerical results. Therefore, as for the AKDQ steel, also for the AA5042 aluminum alloy the material work hardening seems to be not accurately described.

Globally, the absolute value of the percentage error increases with the ironing phase. The results show that for the AA5042 there is a higher dispersion. Nevertheless, it is important to mention that for this material a higher diversity of models and conditions for material parameters identification were used. 

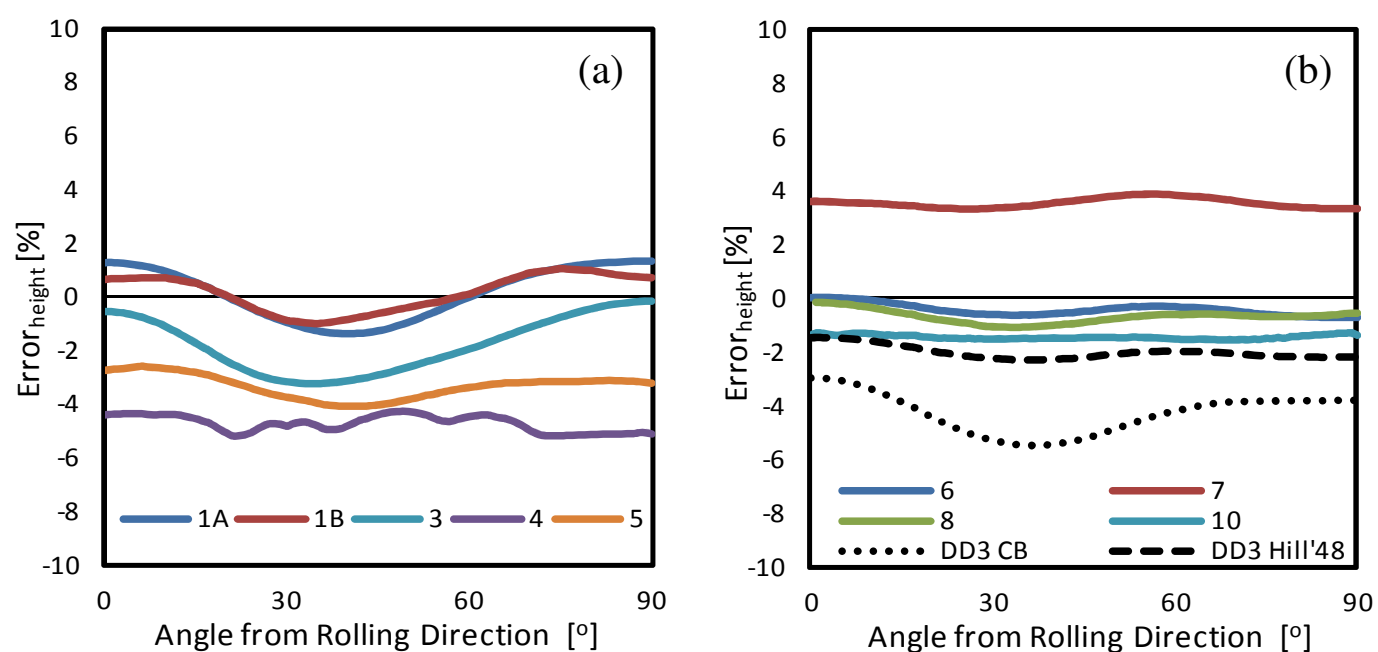

Figure 14. AKDQ earing profile height percentage error after drawing.
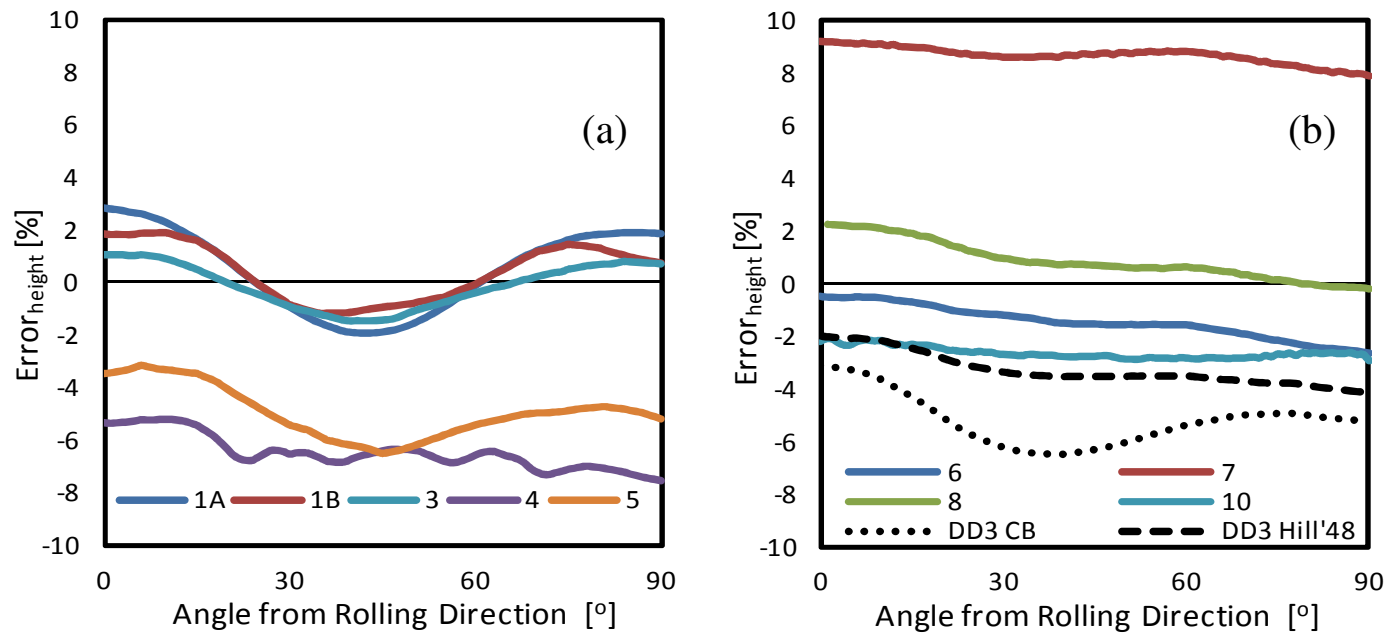

Figure 15. AKDQ earing profile height percentage error after ironing.
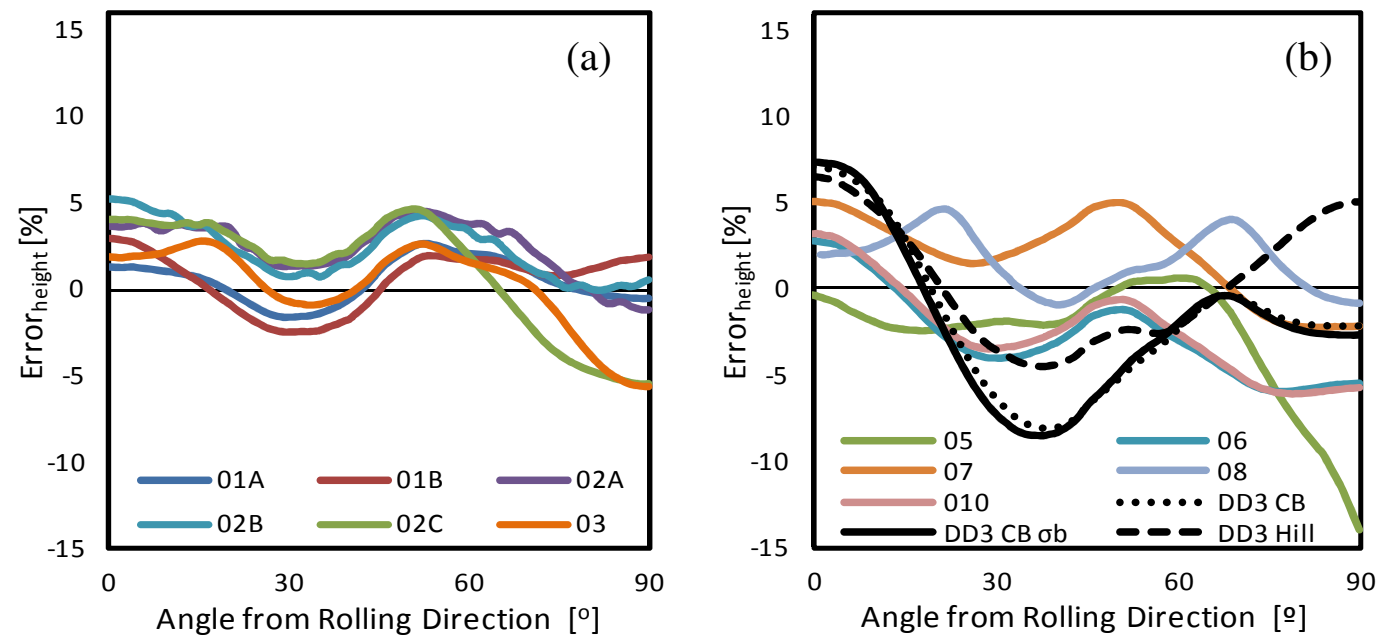

Figure 16. AA5042 earing profile height percentage error after drawing. 

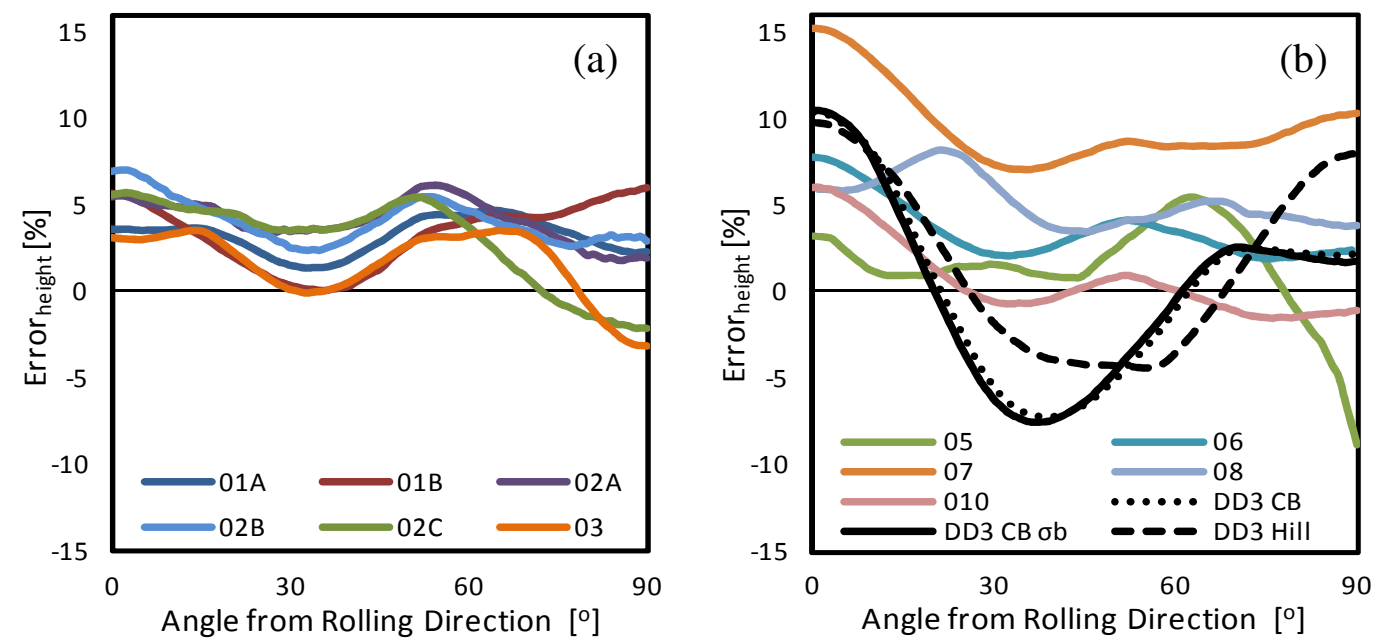

Figure 17. AA5042 earing profile height percentage error after ironing.

\section{CONCLUDING REMARKS}

The earing phenomenon is directly related to the anisotropic behavior of the deep drawn materials. The correct prediction of the cup height not only depends on the correct modeling of the materials mechanical behavior but also on the accuracy of the global process modeling. The numerical analysis of the benchmark conditions, performed using DD3IMP numerical results, indicates that the proposed test can be sensitive to the blank holder modeling. The analysis of the results presented by the NUMISHEET 2011 participants and with DD3IMP code indicates that the results are also sensitive to the yield criterion selected, the work hardening law and the strategy used to identify the materials parameters. Therefore, the accurate prediction of the earing profile, either for drawing or ironing operations, is still a topic of research [26, 33].

\section{Acknowledgements}

This work was co-financed by the Portuguese Foundation for Science and Technology (FCT) via project PTDC/EME-TME/103350/2008 and by FEDER via the "Programa Operacional Factores de Competitividade" of QREN with COMPETE reference: FCOMP-01-0124FEDER-010301.

\section{REFERENCES}

[1] Barlat F., Chung K., Richmond O., "Anisotropic plastic potentials for polycrystals and application to the design of optimum blank shapes in sheet forming". Metall. Mater. Trans. A 25, 1209-1216, 1994.

[2] Bouvier S. Alves J.L., Oliveira M.C., Menezes L.F., "Modelling of anisotropic workhardening behaviour of metallic materials subjected to strain path changes". Comp. Mater. Sci. 32, 301-315, 2005. 
[3] Cazacu O., Barlat F., "Generalization of Drucker's yield criterion to orthotropy". Math. Mech. Solids, 6, 613-630, 2001.

[4] Chen X., Sowerby R., "Blank development and the prediction of earing in cup drawing". Int. J. Mech. Sci. 8, 509-516, 1996.

[5] Chung K., Barlat F., Brem J.C., Lege D.J., Richmond O., "Blank shape design for a plana anisotropic sheet based on ideal sheet forming design theory and FEM analysis". Int. J. Mech. Sci. 39, 105-120, 1997.

[6] Demirci H.I., Esner C., Yasar M., "Effect of the blank holder force on drawing of aluminum alloy square cup: theoretical and experimental investigation". J. Mater. Process. Technol. 206, 152e160, 2008.

[7] Dick R.E.; Yoon J-W.; Huh H.S.; Bae G.; BM1 - Earing Evolution During Drawing and Ironing processes, Part C Benchmark Problems and Results, Proc. of the 8th International Conference and Workshop on Numerical Simulation of 3D Sheet Metal Forming Processes, Huh, H.; Chung, K.; Han, S.S.; Chung, W.J.; (Eds.), 171-226, Kaist Press, 2011.

[8] Gavas M., Izciler M., "Design and application of blank holder system with spiral spring in deep drawing of square cups". J. Mater. Process. Technol. 171, 274-282, 2006.

[9] Hill R., "A Theory of the Yielding and Plastic Flow of Anisotropic Metals". Proc. R. Soc. Lon. Ser.-A, 19, 281-297, 1948.

[10]Lin C.T., Kwan C.T., "Application of abductive network and FEM to predict the optimal blank contour of an elliptic cylindrical cup from deep drawing". J. Mater. Process. Technol. 209, 1351-1361, 2009.

[11]Jahazi M., Goudarzi M., "The influence of thermomechanical parameters on the earing behaviour of 1050 and 1100 aluminium alloys". J. Mater. Process. Technol. 63, 610-613, 1997.

[12] Kanetake N., Tozawa Y., Otani T., "Calculations from texture of earing in deep drawing for FCC metal sheets". Int. J. Mech. Sci. 25, 337-345, 1983.

[13] Kao P.W., "Texture and earing behaviour of cold-rolled aluminium alloy 3004”. Mater. Sci. Eng. 74, 147-157, 1985.

[14] Kim J.H., Lee M.G., Barlat F., Wagoner R.H., Chung K., "An elasto-plastic constitutive model with plastic strain rate potentials for anisotropic cubic metals". Int. J. Plast. 24, 2298-2334, 2008.

[15] Kishor N., Kumar D.R., "Optimization of initial blank shape to minimize earing in deep drawing using finite element method”. J. Mater. Process. Technol. 130-131, 20-30, 2002.

[16] Ku T.W., Kim Y., Kang B.S., "Design and modification of tool to manufacture rectangular cup of NieMH battery for hybrid cars". J. Mater. Process. Technol. 187-188, 197-201, 2007.

[17] Menezes L.F.; Teodosiu C.; "Improvement of the frictional contact treatment in a single loop iteration algorithm specific to deep-drawing simulations". Proc. of NUMISHEET'99 - International Conference on Numerical Simulation of 3D Sheet Forming Processes, Gelin, J.C.; Picart, P.; (Eds.), 197-202, 1999.

[18] Menezes L.F.; Teodosiu C.; "Three-dimensional numerical simulation of the deepdrawing process using solid finite elements", J. Mater. Process. Technol. 97(1-3), 100$106,2000$.

[19] Mulder J., Nový J., Vegter H., "Analytical and numerical simulation of deep drawing and ironing”. Proc. of NUMISHEET'11 - Proc. of the 8th International Conference and Workshop on Numerical Simulation of 3D Sheet Metal Forming Processes, Huh, H.; 
Chung, K.; Han, S.S.; Chung, W.J.; (Eds.), 134-141, Kaist Press, 2011.

[20] Oliveira M.C.; Alves J.L.; Menezes L.F. “One Step Springback Strategies in Sheet Metal Forming”. Proc. of COMPLAS'2003, VII International Conference on Computational Plasticity - Fundamentals and Applications, Owen, D.R.J.; Oñate, E.; Suárez, B.; (Eds.), CIMNE, 87, 2003.

[21] Oliveira M.C.; Alves J.L.; Menezes L.F.; “Algorithms and Strategies for Treatment of Large Deformation Frictional Contact in the Numerical Simulation of Deep Drawing Process", Archives of Computational Methods in Engineering 15:113-162, 2008.

[22] Pegada V., Chun Y., Santhanam S., "An algorithm for determining the optimal blank shape for the deep drawing of aluminum cups". J. Mater. Process. Technol. 125-126, 743-750, 2002.

[23] Rabahallah M., Balan T., Bouvier S., Teodosiu C., "Time integration scheme for elastoplastic models based on anisotropic strain-rate potentials". Int. J. Numer. Methods Eng, 80, 381-402, 2009.

[24] Saha R., Ray R.K., Bhattacharjee D., "Attaining deep drawability and nonearing properties in Tip $\mathrm{Nb}$ interstitial-free steels through double cold rolling and annealing". Scr. Mater. 57, 257-260, 2007.

[25] Soare S., Yoon J.W., Cazacu O., "On the use of homogeneous polynomials to develop anisotropic yield functions with applications to sheet forming”. Int. J. Plast. 24, 915-944, 2008.

[26] Soare S.C., Barlat F., "A study of the Yld2004 yield function and one extension in polynomial form: A new implementation algorithm, modeling range, and earing predictions for aluminum alloy sheets". Eur. J. Mech A-Solid. 30, 6, 807-819, 2011.

[27] Thiruvarudchelvan S., Loh N.H., "Deep drawing of cylindrical cups with friction- actuated blank holding”. J. Mater. Process. Technol. 40, 343-358. 1994.

[28] Thiruvarudchelvan S., "Three novel techniques for forming hemispherical cups with flexible tooling". J. Mater. Process. Technol. 54, 129-136, 1995.

[29] Toh C.H., Kobayashi S., "Deformation analysis and blank design in square cup drawing". Int. J. Mach. Tool Des. Res. 25, 15-32. 1985.

[30] Yoon J.W., Barlat F., Dick R.E., Karabin M.E., "Prediction of six or eight ears in a drawn cup based on a new anisotropic yield function". Int. J. Plast. 22, 174-193, 2006.

[31] Yoon J.H., Cazacu O., Yoon J.W., Dick R.E., "Earing predictions for strongly textured aluminum sheets”. Int. J. Mech. Sci. 52, 12, 1563-1578, 2010.

[32] Yoon J.H., Cazacu O., "Anisotropic yield function capable of predicting eight ears". Proc. of NUMISHEET'11 - Proc. of the 8th International Conference and Workshop on Numerical Simulation of 3D Sheet Metal Forming Processes, Huh, H.; Chung, K.; Han, S.S.; Chung, W.J.; (Eds.), 86-91, Kaist Press, 2011.

[33] Yoon J.W., Dick R.E., Barlat F., "A new analytical theory for earing generated from anisotropic plasticity". Int. J. Plast. 27, 1165-1184, 2011.

[34] Yu T.M., Brooks C.R., Goodrich S., "The effect of cold working and annealing practice on earing in 3104 AI alloy sheet". Mater. Charact. 30, 251-259, 1993.

[35]Zaky A.M., Nassr A.B., El-Sebaie M.G., "Optimum blank shape of cylindrical cups in deep drawing of anisotropic sheet metals". J. Mater. Process. Technol. 76, 203-211, 1998. 